\title{
CAPITULO 80 \\ PREVENÇÃO E PROMOÇÃO DA SAÚDE NA ESCOLA: RELATO DE EXPERIÊNCIA
}

DOI 10.4322/978-65-995353-2-1.c80

\begin{abstract}
Antônio Lucas Farias da Silva ${ }^{1}$, José de Ribamar Gomes da
Silva Júnior ${ }^{2}$, Bianca Gisele Lira Gonzaga Sobrinho ${ }^{3}$, Leonardo César Soares Maia ${ }^{4}$, Matheus Rodrigues Santos ${ }^{5}$, DivaNina Melo Machado $^{6}$, Lucília da Costa Silva ${ }^{7}$ Janiele Soares de Oliveira ${ }^{8}$, Emanuel Osvaldode Sousa ${ }^{9}$, Geísa de Morais Santana ${ }^{10}$.

${ }^{1}$ Centro Universitário Unifacid, (lucas1992farias@ gmail.com)

${ }^{2}$ Centro Universitário Unifacid, (ribamar.jr19@ outlook.com)

${ }^{3}$ Centro Universitário Unifacid, (biancagonzagapi@gmail.com)

${ }^{4}$ Centro Universitário Unifacid, (Leo.583@ hotmail.com)

${ }^{5}$ Centro Universitário Unifacid, (matheus.rodrigues.97.mr@gmail.com)

${ }^{6}$ Centro Universitário Unifacid,(fisioninamelo@gmail.com)

${ }^{7}$ Centro Universitário Santo Agostinho, (luciliafisio@outlook.com)

${ }^{8}$ Associação de Ensino Superior doPiauí-AESPI, (janysoares276@gmail.com)

${ }^{9}$ Pós: Fisioterapia Traumato OrtopédicaUESPI, (emanfisio@ hotmail.com)

${ }^{10}$ Universidade Estadual do Piauí, (geisasantana97@gmail.com)
\end{abstract}

Palavras-chave: Promoção da Saúde; Saúde Escolar; Saúde do Adolescente.

Área Temática: Ciências da Saúde.

E-mail do autor principal: lucas1992farias@ gmail.com

\section{RESUMO}

Objetivo: Relatar a experiência de um projeto de extensão universitária na realização de oficinas de educação em saúde em uma escola municipal do interior de José de Freitas PI. Metodologia: Trata-se de um estudo descritivo do tipo relato de experiência, realizado no período de Março a Agosto de 2018 na Escolar Municipal Joaquim Euclides da Rocha,

\section{E - book Tripé do Ensino Superior: Ensino,} Pesquisa e Extensão 
localizada na comunidade Graciosa, interior da cidade de José de Freitas PI. O projeto foi composto por acadêmicos da área da saúde, os encontros ocorriam com periodicidade quinzenal com duração de 2 horas por encontro. Os encontros tinham a participação de crianças e adolescentes do ensino fundamental e médio. Resultados: A escola é espaço de grande relevância para promoção da saúde, principalmente quando exerce papel fundamental na formação do cidadão crítico, estimulando a autonomia, o exercício de direitos e deveres, o controle das condições de saúde e qualidade de vida, com opção por atitudes mais saudáveis. Os encontros eram feitos através de rodas de conversa, voltadas para um tema específico em cada dia, sempre tentando fazer de forma lúdica, no intuito de fazer com que as crianças tivessem interesse em participar das atividades propostas. Conclusão: Ações de educação em saúde permitem um espaço de troca entre o saber popular e o saber científico, além de permitir a construção de vínculo entre os profissionais de saúde e os usuários.

\section{INTRODUÇÃO}

O programa saúde na escola (PSE), foi instituído pelo Decreto Presidencial $\mathrm{n}^{\circ}$ 6.286/2007 e caracteriza-se por ser uma política intersetorial que atende aos princípios e diretrizes do Sistema Único de Saúde (SUS) (MINISTÉRIO DA SAÚDE, 2009). O programa se propõe a ser um modelo de atenção à saúde com finalidade de contribuir para a formação integral dos escolares da rede básica por meio de ações de prevenção, promoção e atenção à saúde. As ações são planejadas pelas secretarias de saúde e de educação, como também, podem ser planejadas por demanda solicitada pelos diretores das escolas (MINISTÉRIO DA EDUCAÇÃO, 2011)

A escola, que tem como missão primordial desenvolver processos de ensinoaprendizagem, desempenha papel fundamental na formação e atuação das pessoas em todas as arenas da vida social. Juntamente com outros espaços sociais, ela cumpre papel decisivo na formação dos estudantes, na percepção e construção da cidadania e no acesso às políticas públicas. Desse modo, pode tornar-se locus para ações de promoção da saúde para crianças, adolescentes e jovens adultos (DEMARZO; AQUILANTE, 2008).

A adolescência é considerada um rito de passagem da fase infantil para a fase adulta. De acordo com a Organização Mundial de Saúde (OMS) e a Organização Pan Americana de Saúde (OPAS), a adolescência consiste entre o período de vida de 10 a 19 anos, etapa em que ocorre um complexo processo de aceleração do crescimento e desenvolvimento biopsicossocial e da personalidade (CONCEIÇÃO; MACEDO, 2013).

É notório que na fase da adolescência, muitos hábitos e atitudes comportamentais, sofrerão variações na idade adulta, tornando-se mais difíceis de serem contornados. Dessa 
forma, é fundamental despertar no adolescente o desejo de se tornar agente ativo do seu autocuidado, valendo-se para isso de métodos de educação em saúde que direcionem à promoção da saúde, a prevenção de doenças e o autocuidado (VIERO et al., 2015).

Segundo Martins et al. (2019), existe uma elevada resistência dos jovens a se aproximarem dos serviços de saúde, podendo estar atrelada ao despreparo dos profissionais desde o acolhimento, através de uma escuta desqualificada, descontinuidade da assistência e a não vinculação. No intuito de enfrentar e transformar essa realidade, faz-se necessários implementar estratégias educativas que alcancem os sujeitos. Sob essa ótica, a Promoção da saúde é compreendida como um instrumento eficaz no desenvolvimento da autonomia, contribuindo para melhoria das condições de vida. (BRASIL, 2006; TEIXEIRA et al., 2014).

A promoção de saúde deve ocorrer de maneira eficaz e não impositiva, priorizando-se práticas que respeitem as diferenças dos envolvidos, fazendo da educação em saúde uma verdadeira ferramenta de empoderamento do indivíduo (SPERÂNDIO, A. M. et al.). Para crianças e adolescentes, a escola é o melhor local para a prática da educação em saúde, porque este espaço é adequado para promover ações educativas com o envolvimento de diferentes grupos sociais, onde se destaca a coparticipação dos escolares, dos pais, educadores e profissionais da saúde, que juntos têm uma maior chance de encontrar soluções para os mais diversos problemas (FERREIRA, I. R. et al.).

Portanto, os processos de educação em saúde na escola ajudam crianças e adolescentes a adquirirem um comportamento social voltado aos melhores métodos de prevenção aos problemas de saúde, como também, esclarecer a população no sentido de adotar um estilo de vida saudável (EBERHARDT, T. D. et al.). Neste contexto, os acadêmicos da área da saúde podem contribuir de forma positiva, exercendo além de suas obrigações dentro da Universidade, atuando no papel de educador, trabalhando com a realização de atividades que estimulem a saúde e a qualidade de vida por meio da educação.

Para que a atenção à saúde atinja seu objetivo, além do esforço dos profissionais de saúde, é de fundamental importância o interesse e participação dos educadores e diretores da escola em fazer chegar até o escolar as informações mínimas necessárias ao esclarecimento de atividades que garantem a promoção à saúde, assim como, as orientações para cuidados diários que o escolar pode fazer em casa, na escola e em sua vida cotidiana (MINISTÉRIO DA SAÚDE, 2009).

\section{E - book Tripé do Ensino Superior: Ensino, Pesquisa e Extensão}


O adolescente tem a característica de conviver em grupo para a busca da sua identidade e resposta a seus anseios. Geralmente se agrupa com jovens que possuem as mesmas qualidades, gostos e interesses (QUINTANA; ROSSI; VELHO, 2014). Partindo desse princípio, a maioria das atividades eram feitas em grupo, visando com que os adolescentes se sentissem mais a vontade para participar.

A partir da conjuntura anteriormente apresentada, o objetivo deste trabalho é relatar a experiência de um projeto de extensão universitária na realização de oficinas de educação em saúde em uma escola municipal do interior de José de Freitas PI.

\section{METODOLOGIA}

O relato de experiência, segundo o Instituto de Ciências da Vida, da Universidade Federal de Juiz de Fora [2017] é um texto que descreve precisamente uma dada experiência que possa contribuir de forma relevante para sua área de atuação. Segundo este instrutivo de elaboração de relatos de experiência [2017], ele apresenta as motivações ou metodologias para as ações tomadas na situação e as considerações/impressões que a vivência trouxe àquele (a) que a viveu.

Trata-se de um estudo descritivo do tipo relato de experiência, realizado no período de Março a Agosto de 2018 na Escolar Municipal Joaquim Euclides da Rocha, localizada na comunidade Graciosa, interior da cidade de José de Freitas PI. O projeto teve apoio da Universidade Estadual do Piauí (UESPI). O projeto foi composto por acadêmicos da área da saúde, os encontros ocorriam com periodicidade quinzenal com duração de 2 horas por encontro, a escolha dessa escola justificou-se pela precariedade de acesso as informações sobre saúde e qualidade de vida.

Os encontros tinham a participação de crianças e adolescentes do ensino fundamental e médio. Enquanto ocorriam os encontros com as crianças, uma parte dos acadêmicos ficavam responsáveis por trazer temas sobre saúde para os funcionários, professores e os pais dos alunos que aguardavam no local. Ao término de todos os encontros foi disponibilizado pelo diretor da escola, lanche para todos os participantes do projeto.

\section{RESULTADOS E DISCUSSÃO}

No contexto situacional do espaço escolar, encontram-se diferentes sujeitos, com histórias e papéis sociais distintos - professores, alunos, merendeiras, porteiros, pais, mães,

\section{E - book Tripé do Ensino Superior: Ensino,} Pesquisa e Extensão 
avós, avôs, voluntários, entre outros -, que produzem modos de refletir e agir sobre si e sobre o mundo e que devem ser compreendidos pelas equipes de Saúde da Família em suas estratégias de cuidado.

A escola é espaço de grande relevância para promoção da saúde, principalmente quando exerce papel fundamental na formação do cidadão crítico, estimulando a autonomia, o exercício de direitos e deveres, o controle das condições de saúde e qualidade de vida, com opção por atitudes mais saudáveis. As iniciativas de promoção da saúde escolar constituem ações efetivas para a consecução dos objetivos citados, o que pode ser potencializado no Brasil pela participação ativa das equipes de Saúde da Família (DEMARZO; AQUILANTE, 2008), sempre em associação com as equipes de educação.

Os encontros eram feitos através de rodas de conversa, voltadas para um tema específico em cada dia, sempre tentando fazer de forma lúdica, no intuito de fazer com que as crianças tivessem interesse em participar das atividades propostas. Os adolescentes mostraram-se muito participativos, questionadores e interativos. Durante a roda de conversa percebeu-se muitas curiosidades e perguntas a respeito da sexualidade, das doenças sexualmente transmissíveis e relatos de alto índice de gravidez na adolescência na comunidade.

Percebeu-se também a falta de informação sobre os métodos contraceptivos e sobre as principais informações sobre o HIV, então foi proposto uma competição entre 04grupos, onde era dito uma frase e os adolescentes julgavam se era verdade ou mito, depois discutia-se sobre o assunto.

A imagem 01 representa o primeiro encontro que teve como tema o que é saúde? As crianças foram divididas em grupos para que houvesse uma discussão sobre o tema e cada grupo fazia suas considerações sobre o tema, logo em seguida os acadêmicos complementavam com outras informações relevantes sobre saúde. 
Imagem 01: Discussão em grupo sobre o que é saúde.

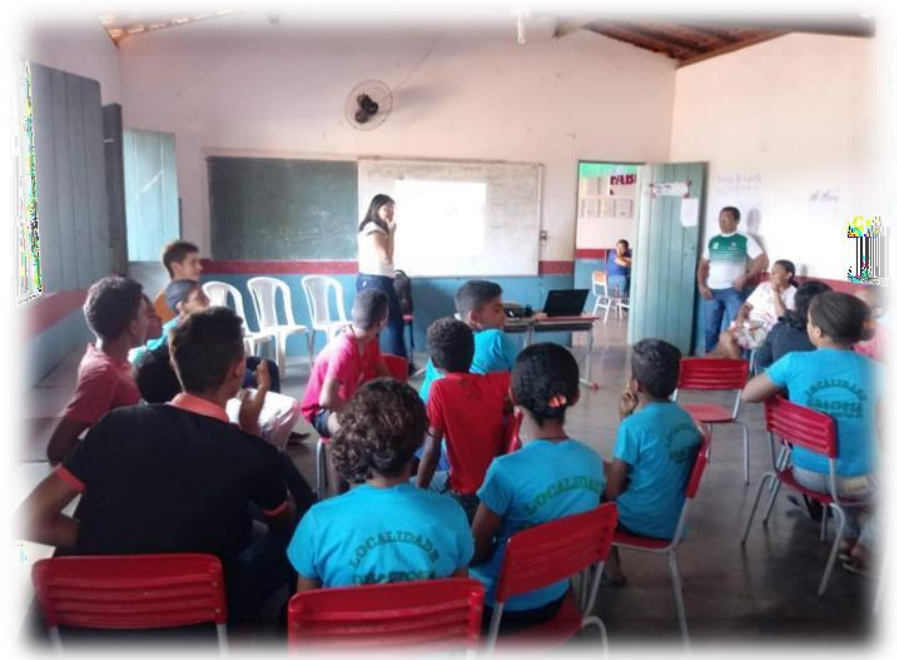

\section{Fonte: Própria}

Segundo a Organização Mundial da Saúde (OMS), entende-se como Educação em Saúde a combinação de ações e experiências de aprendizado planejado com o intuito de habilitar as pessoas a obterem conhecimento sobre fatores determinantes e comportamentos de saúde. São várias as modalidades de Educação em Saúde e todas evidenciam a mudança de hábitos, atitudes e comportamentos individuais e coletivos. Essas mudanças de comportamentos estão atreladas à aquisição de novos conhecimentos e à adoção de atitudes favoráveis à saúde.

Imagem 02: Importância da boa postura.

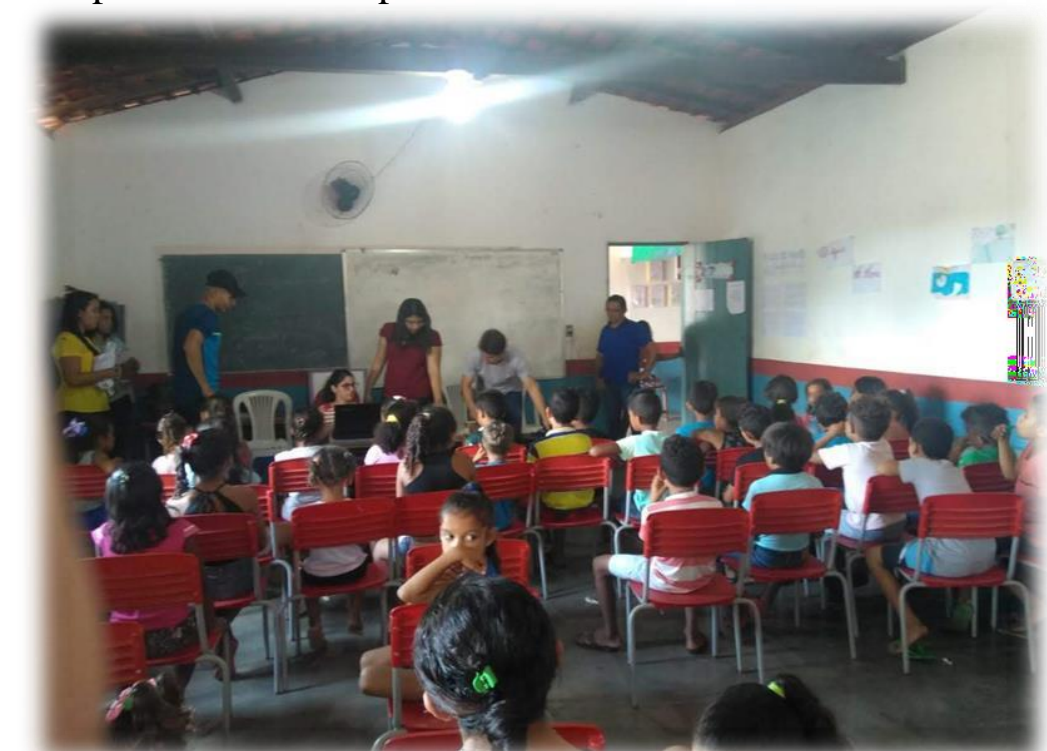

Fonte: Própria

\section{E - book Tripé do Ensino Superior: Ensino,} Pesquisa e Extensão 
$\mathrm{Na}$ imagem 02, os acadêmicos falaram sobre os benefícios da boa postura e sua importância para a saúde. Foi criado um mural com as posturas CORRETAS X ERRADAS, o mesmo ficou exposto na escola para que todos pudessem ter acesso às informações sobre uma boa postura. Ao todo ocorreram 12 encontros e todos eram voltados para atividades em grupo, sempre iniciando com discussões sobre o tema específico de cada dia. Os momentos de troca, sejam através de perguntas e repostas ou através de falas voluntárias, engrandeceram a roda, faziam com que cada participante se envolvesse com a atividade, estando e sentindo-se livre para expor suas ideias, conceitos e dúvidas.

Quadro 01: Temas abordados nos encontros.

\begin{tabular}{|c|l|}
\hline SEXUALIDADE & $\begin{array}{l}\text { Inicialmente, foi feita uma roda de conversa para } \\
\text { para discussão sobre o tema, logo após, os } \\
\text { acadêmicos sanaram todas as dúvidas das } \\
\text { crianças e repassaram informações importantes } \\
\text { sobre o tema. }\end{array}$ \\
\hline DOENÇA SEXUALMENTE & $\begin{array}{l}\text { Os acadêmicos falaram sobre a importância da } \\
\text { prevenção das DST's, como também, sobre suas } \\
\text { causas e possíveis complicações da doença. Ao } \\
\text { término do encontro foi feito um jogo de MITOS } \\
\text { X VERDADES sobre o tema. }\end{array}$ \\
\hline DRANSMISSÍVEIS (DST) & $\begin{array}{l}\text { Ocorreu uma discussão em grupo sobre o tema, } \\
\text { em seguida os acadêmicos fizeram um jogo de } \\
\text { perguntas e respostas. Logo após, abordamos } \\
\text { questões relacionadas aos tipos de drogas e } \\
\text { trocamos experiências de falas e contatos com } \\
\text { amigos usuários. Discutimos os conceitos de uso, } \\
\text { abuso e dependência, bem como os efeitos das } \\
\text { substâncias no organismo humano. }\end{array}$ \\
\hline
\end{tabular}




\begin{tabular}{|l|l|}
\hline GRAVIDEZ & $\begin{array}{l}\text { Inicialmente, os adolescentes foram divididos em } \\
\text { grupos por sexo, para deixar as meninas mais à } \\
\text { vontade para falarem sobre o tema, logo após, } \\
\text { foram abordadas questões sobre formas de } \\
\text { prevenção e a importância do pré-natal. }\end{array}$ \\
\hline FAMÍLIA & $\begin{array}{l}\text { Durante a roda de conversa, cada criança e } \\
\text { adolescente puderam falar sobre sua família e foi } \\
\text { percebido uma grande diversidade das mesmas. } \\
\text { No final do encontro os acadêmicos falaram } \\
\text { sobre a importância da família para o } \\
\text { desenvolvimento e crescimento das pessoas. }\end{array}$ \\
\hline
\end{tabular}

Visando lograr a integralidade do enfoque da área da saúde, a Organização PanAmericana de Saúde (OPAS) propõe a utilização de técnicas e métodos participativos que ultrapassem a delimitação física da escola e envolvam pais, professores e comunidades. Metodologias dessa natureza devem permear todas as atividades desenvolvidas, tais como diagnóstico das necessidades de saúde da população escolar; desenvolvimento curricular de forma integrada; preparação de material didático; formação permanente de professores e funcionários; investigação, seguimento e avaliação das atividades desenvolvidas; e difusão de informações sobre os avanços e desafios encontrados (BRASIL, 2006a).

A roda de conversa é, portanto, muito importante no dia a dia da educação infantil, pois é um momento de partilha, aprendizagens, em que a criança aprende a conversar, pois a roda é para conversar e não apenas para ocupar tempo como afirmou a autora Bombassaro (2010). Desta forma os acadêmicos devem explorar esse momento, buscando trazer temáticas em que envolvam o grupo todo, para que haja uma participação ativa na roda.

\section{CONCLUSÃO}

Ações de educação em saúde permitem um espaço de troca entre o saber popular e o saber científico, além de permitir a construção de vínculo entre os profissionais de saúde e os usuários. Promovemos discussões e compartilhamos conhecimentos e experiências durante

\section{E - book Tripé do Ensino Superior: Ensino, Pesquisa e Extensão}


toda a condução do projeto. A partir das rodas de conversas com os adolescentes aprendemos conhecimentos que se somaram e se multiplicaram a cada etapa concluída.

Dessa forma, foi possível observar que o projeto foi de grande valia para as crianças e adolescentes, assim como, para os acadêmicos envolvidos, que obtiveram um grande crescimento pessoal e profissional.

\section{REFERÊNCIAS}

BOMBASSARO, Maria Cláudia. A Roda na Educação Infantil: Aprendendo a Roda aprendendo a conversar.2010. 96f. Dissertação ( Mestrado) -Faculdade de Educação.

Universidade Federal do Rio Grande do Sul, Porto Alegre.

766

BRASIL. Ministério da Saúde; ORGANIZAÇÃO PAN-AMERICANA DA SAÚDE. Escolas Promotoras de Saúde: experiências do Brasil. Brasília: Editora do Ministério da Saúde, 2006a.

BRASIL, Ministério da Saúde. Portaria nº 687, de 30 de março de 2006. Política Nacional de

Promoção da Saúde. Brasília, DF. Disponível em: https://bvsms.saude.gov.br/ bvs/publicacoes/politica_promocao_saude.pdf. Acesso em: 04 maio 2019.

CONCEICAO, M. I. G.; MACEDO, E. O. S. Ações em grupo voltadas à promoção da saúde de adolescentes. Rev. bras. Crescimento Desenvolv. Hum., São Paulo, v. 23, n. 2, p. 222-230, 2013. Disponível em: http://pepsic. bvsalud.org/scielo.php?script=sci_arttext\&pid=S0104$12822013000200016 \& \operatorname{lng}=$ pt\&nrm=iso. Acesso em: 02 maio 2019.

DEMARZO, M. M. P.; AQUILANTE, A. G. Saúde Escolar e Escolas Promotoras de Saúde. In: Programa de Atualização em Medicina de Família e Comunidade. Porto Alegre, RS: Artmed: Pan-Americana, 2008. v. 3, p. 49-76.

EBERHARDT, T. D, Reis LF. Programa Saúde na Escola - PSE: estruturado de acordo com os princípios do SUS?. Anais do $5^{\circ}$ Seminário Nacional Estado e Políticas Sociais. As políticas sociais nas transições latinoamericanas no século XXI: tendências e desafios. Cascavel, Paraná; 9-12 out 2011. Cascavel (PR): Universidade Estadual do Oeste do Paraná (UNIOESTE); 2011. p. 1-14.

FERREIRA IR, Vosgerau DS, Moysés SJ, Moysés ST. Normative measures of the Health in the School Program: content analysis associated with ATLAS TI software. Ciênc Saúde Coletiva. 2012 Dez;17(12):3385-98. DOI: https://doi.org/10.1590/s1413-81232012001200023 
MARTINS, M. M. F. et al. Acesso aos serviços de atenção primária à saúde por adolescentes e jovens em um município do Estado da Bahia, Brasil. Cad. Saúde Pública, Rio de Janeiro, v. 35, n. $\quad 1, \quad 2019 . \quad$ Disponível em: https:// www.scielo.br/scielo.php?script=sci_arttext\&pid=S0102-

311X2019000105007\&lng=en\&nrm=iso. Acesso em: 02 maio 2019.

Ministério da Saúde (BR). Secretaria de Atenção à Saúde. Departamento de Atenção Básica. Saúde na escola. Cadernos de Atenção Básica, n. 24. Série B. Textos Básicos de Saúde. Brasília (DF): Ministério da Saúde; 2009.

Ministério da Educação (BR). Secretaria da Educação Básica. Diretoria de Currículos e Educação Integral. Manual da educação integral em jornada ampliada para obtenção de apoio financeiro por meio do programa dinheiro direto na escola-PDE/educação integral: no exercício de 2011. Brasília (DF): Ministério da Educação; 2011.

QUINTANA, A. M.; ROSSI, A. G.; VELHO, M. T. A. C. Adolescência, autonomia e pesquisa em seres humanos. Rev. Bioét., Brasília, v. 22, n. 1, p.76-84, abr., 2014. Disponível em: https://www.scielo.br/scielo.php?script=sci_arttext\&pid=S198380422014000100009\&lng=en \&nrm=i so. Acesso em: 03 maio 2019.

SPERÂNDIO AM, Carvalho FFB, Nogueira J, Zancan L, Akerman M. 10 years of the National Health Promotion Policy: progress and challenges. Ciênc Saúde Coletiva. 2016 Jun;21(6):16812. DOI: https://doi.org/10.1590/1413-81232015216.10862016

VIERO, V. S. F. et al. Educação em saúde com adolescentes: Análise da aquisição de conhecimentos sobre temas de saúde. Esc. Anna Nery, v.19, n. 3, p. 484- 490, 2015. Disponível em: https://www.scielo.br/pdf/ean/ v19n3/1414-8145-ean-19-03-0484.pdf. Acesso em: 15 jan. 2019.

\section{E - book Tripé do Ensino Superior: Ensino,} Pesquisa e Extensão 